\title{
ANALYSIS AND MODELING TIME HEADWAY DISTRIBUTIONS UNDER HEAVY TRAFFIC FLOW CONDITIONS IN THE URBAN HIGHWAYS: CASE OF ISFAHAN
}

\author{
Sayyed Mahdi Abtahi ${ }^{1}$, Mohammad Tamannaei ${ }^{2}$, Hosein Haghshenash ${ }^{3}$ \\ 1, 2 Dept of Civil Engineering, Isfahan University of Technology, Isfahan, Iran \\ ${ }^{3}$ Dept of Civil Engineering, Sharif University of Technology, Tehran, Iran \\ E-mails: ${ }^{1}$ mabtahi@cc.iut.ac.ir; ${ }^{2}$ m.tamannaei@cv.iut.ac.ir (correspondingauthor); \\ 3ho_hagh@yahoo.com
}

Submitted 17 December 2010; accepted 25 January 2011

\begin{abstract}
The time headway of vehicles is an important microscopic traffic flow parameter which affects the safety and capacity of highway facilities such as freeways and multi-lane highways. The present paper intends to provide a report on the results of a study aimed at investigating the effect of the lane position on time headway distributions within the high levels of traffic flow. The main issue of this study is to assess the driver's behavior at different highway lanes based on a headway distribution analysis. The study was conducted in the city of Isfahan, Iran. Shahid Kharrazi six-lane highway was selected for collecting the field headway data. The under-study lanes consisted of passing and middle lanes. The appropriate models of headway distributions were selected using a methodology based on Chi-Square test for each lane. Using the selected models, the headway distribution diagrams were predicted for high levels of traffic flow in both the passing and middle lanes and the relationship between statistical criteria of the models and the driver's behaviors were analyzed. The results certify that the appropriate model for the passing lane is different than the one for the middle lane. This is because of a different behavioral operation of drivers which is affected by specific conditions of each lane. Through car-following conditions in the passing lane, a large number of drivers adopt unsafe headways. This shows high risk-ability of driver population which led to considerably differences in capacities and statistical distribution models of two lanes.
\end{abstract}

Keywords: headway, distribution, model, car-following, driver behavior, traffic flow, passing and middle lanes.

\section{Introduction}

The time headway or headway is 'the time, in seconds, between two successive vehicles as they pass a point on the roadway, measured from the same common feature of both vehicles' (Highway Capacity Manual 2000). This parameter is one of the fundamental microscopic traffic flow characteristics. These characteristics are of great importance for planning, analyzing, designing and operating roadway systems (Jakimavičius, Burinskienè 2009; Mesarec, Lep 2009). Therefore, it must be analyzed as accurate as possible based on real behavior of drivers (Kerner 2009). Traffic engineers and planners should be well aware of real behaviors of drivers in choosing the desired headways. In fact they should be able to predict the driver's behaviors while facing the headways in order to have better planning and traffic managing through different conditions. This is because of the fact that time headways and their distributions would affect different flow parameters including capacity, level of service and safety (Thamizh Arasan, Koshy 2003). Precise modeling and analysis of vehicle headway distribution helps traffic engineers to maximize roadway capacity and minimize vehicle delays (Zhang et al. 2007). Headway distributions are also needed to run digital simulations through modeling multilane traffic in driving simulators (Zwahlen et al. 2007). Moreover, with headway analysis it is possible to get cognition from the reasons of accidents and the ways for increasing the road safety. It should be pointed out that in most capacity modeling; the safety headway requirement is not taken into account during the model calibration and parameter estimation. This may partly explain why some problems are often experienced on roadways carrying less traffic than the perceived capacity (Yi et al. 2004).

There are different factors affecting the time headway distribution of vehicles and their suitable models such as traffic volume, ratio of large sized or heavy vehicles mixed in, lane position, road structure, daytime or 
night time and weather (Daisuke et al. 1999). Some studies have investigated the headway distributions in freeways and highways. Mei and Bullen (1993) investigated different statistical distributions for headways measured on two southbound lanes of a four-lane highway during the morning peak period. It was concluded that at both selected lanes, the lognormal distribution with a shift of 0.3 or 0.4 seconds was the best model for the time headways in high traffic flows. In a study conducted in interstate highways of Illinois, U.S. by Sadeghhosseini (2002), the headways were collected at the flow rates varying from 140 to 1704 vehicles per hour per lane. The study recommended using the lognormal model with a shift of 0.36 seconds to generate the time headway distribution for any traffic volume for both left and right lanes. In another study, Thamizh Arasan (2003) investigated the headway data collected from a four-lane divided urban arterial in Chennai City in India. The negative exponential statistical distribution was found to be suitable for modeling headways over the entire range of traffic flow and different lanes. Bham and Ancha (2006), surveyed time headways of drivers in steady state car-following for different types of freeway sections. The data sites contained a basic freeway section, a ramp merge, a lane drop and a ramp weave section. It was found that the shifted lognormal distribution provided a better fit for all the mentioned sites compared to the shifted gamma distribution. Al-Ghamdi (2001) carried out an analysis on time headways observations on urban roads in Riyadh, Saudi Arabia. The flow range of the vehicles observed was divided into three classifications of low ( $<400 \mathrm{vph})$, medium $(400 \div 1200 \mathrm{vph})$, and high (>1200 vph) levels of traffic flow. Following his data analysis, he found that the best models for headways in low, medium and high levels of flow were negative-exponential, shifted-exponential and Erlang distributions, respectively. Meanwhile, he added that most of the researches conducted so far on headway distributions have focused on low traffic conditions. The headway distribution modeling is, however, still vague in high levels of traffic flow. Luttinen (1996) performed a thorough analysis of vehicle headways collected from rural highways in Finland. He concluded that the gamma distribution can be used for low-to-moderate traffic volumes which have low probability for short headways. He also suggested that despite the fact that lognormal distribution is neither simple nor realistic enough, it can be considered as a model for the follower headway distribution (Luttinen 1994). Zwahlen et al. (2007) investigated the portability of the cumulative headway distributions for different traffic volumes and traffic lanes in Ohio freeways. The results of the research showed that the headway distributions for different lanes are nearly the same for similar hourly traffic volumes. Daisuke et al. (1999) collected headway data from different sites in Japan and used Synthetic erlang distribution model to investigate the effects of some factors on time headway distribution. They also attempt to find a law in relation with the model parameters. It was learnt through results that each lane has a specific background that may affect time headway distribution.
The majority of past studies were performed based on entire headway data collected from a highway without separating data of each lane. Also, most of those studies were undertaken under low or medium flow rate conditions. The present paper intends to provide a report on the results of a study aimed at investigating the effect of lane position on time headway distributions within high levels of traffic flow. The main issue of this study is to assess the driver behaviors at two highway lanes based on headway distribution analysis. Shahid Kharrazi six-lane highway was selected for collecting the field headway data. The under-study lanes consisted of the passing and middle lanes. The appropriate models of headway distributions were selected in a Chi-Square test based methodology for each lane and the relationship between statistical criteria of the selected models and the driver behaviors in the lanes were analyzed.

\section{Data Collection and Primary Analysis}

The field data were collected in Isfahan, Iran. Isfahan is a metropolitan area with a population of over 1600000 . The data collection was done by videotaping a ninetymeter long basic section, picked from Shahid Kharrazi six-lane highway on December, 2009 (Fig. 1). The highway is a part of Isfahan third traffic ring, which is under uninterrupted flow conditions. A video camera was mounted on the top of a high building adjacent to the highway, to capture continuously the moving traffic in different hours of the day. After reviewing the films, a 90 minutes time-study of morning peak hours was selected for data extraction. The time-study was selected so that the traffic flows were at the high levels. The extracted data were from two lanes: the passing lane adjacent to the highway median (named as left lane or lane 3 ) and middle lane (lane 2). For each lane, the time-study was divided into eighteen consecutive 5-minute time intervals. Using Ulead Video Studio software, the moments in which each vehicle passed from the marker installed next to the road (reference point), were recorded. The accuracy of the operation was 1:30 seconds. Totally, about 5400 time headways were recorded from both lanes

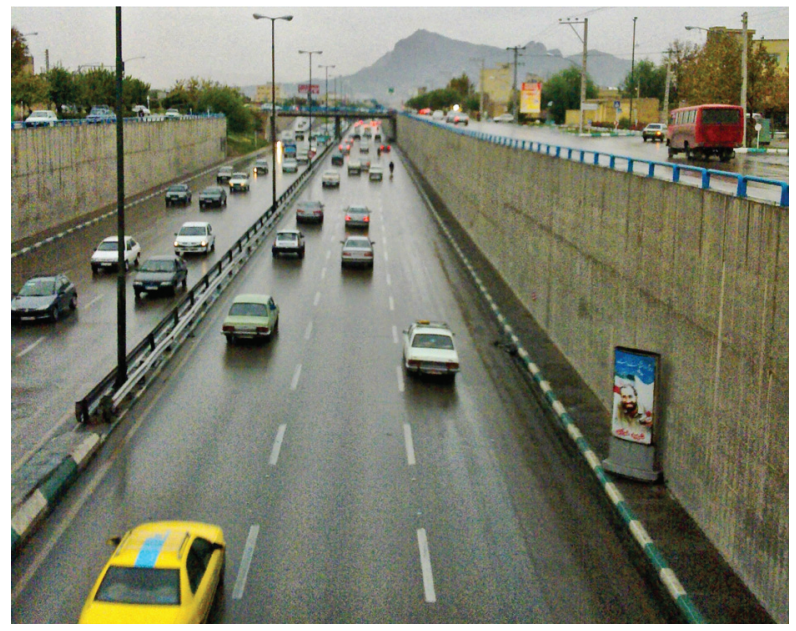

Fig. 1. A view of the selected basic section 
( 3 and 2). It is worth mentioning here that the dominant part of traffic composition at both lanes was related to passengers' cars. At the mentioned time-study, the percentage of passengers' cars in the passing lane and the middle lane were 97.2 and 90.6 , respectively.

In order to obtain the flow rate of each time-interval, vehicle flows were converted into passenger-car flows using passenger-car equivalents suggested by Highway Capacity Manual (2000). The traffic flow rate ranged from about 1800 passenger's car per hour per lane ( $\mathrm{pc} / \mathrm{h} / \mathrm{ln}$ ) to over $2500 \mathrm{pc} / \mathrm{h} / \mathrm{ln}$ for passing lane. That was about 1400 to $2000 \mathrm{pc} / \mathrm{h} / \mathrm{ln}$ for the middle lane. Also, the space, mean speed was determined for each 5 -minute time interval. Therefore, a sample size of 30 vehicles was selected randomly from each lane for this purpose, and the passing time of each vehicle through the basic section was calculated. The main statistical characteristics of data collected from two lanes are shown in Table 1.

Table 1. Statistical characteristics of the collected data

\begin{tabular}{lcc}
\hline $\begin{array}{c}\text { Characteristics of } \\
\text { Traffic Observed }\end{array}$ & $\begin{array}{c}\text { Passing Lane } \\
\text { (Lane 3) }\end{array}$ & $\begin{array}{c}\text { Middle Lane } \\
\text { (Lane 2) }\end{array}$ \\
\hline Sample Size & 3049 & 2344 \\
\hline Mean Flow Rate $(\mathrm{pc} / \mathrm{h} / \mathrm{ln})$ & 2146 & 1688 \\
\hline Max Flow Rate $(\mathrm{pc} / \mathrm{h} / \mathrm{ln})$ & 2608 & 1958 \\
\hline Min Flow Rate $(\mathrm{pc} / \mathrm{h} / \mathrm{ln})$ & 1842 & 1518 \\
\hline Passenger Car $(\%)$ & 97.2 & 90.6 \\
\hline Space Mean Speed $(\mathrm{km} / \mathrm{h})$ & 87.3 & 79.4 \\
\hline Mean of Headways $(\mathrm{sec})$ & 1.69 & 2.18 \\
\hline Median of Headways $(\mathrm{sec})$ & 1.30 & 1.78 \\
\hline Max Headways $(\mathrm{sec})$ & 12.77 & 11.62 \\
\hline Min Headways $(\mathrm{sec})$ & 0.13 & 0.12 \\
\hline
\end{tabular}

According to the Table 1, the mean flow rate in the passing lane is higher than the mean flow rate in the middle lane. This shows that the lane utilization by vehicles is not homogenous for both lanes at the peak hours of traffic. Several driver training programs state that 2 seconds is the minimum headway for safe following (Michael et al. 2000). The Table 1 also shows that high flow conditions, a high percent of drivers in the passing lane and more than half of drivers in the middle lane choose the headways less than safe headway.

This is because of the fact that the mean value and median value of headways in the passing lane and median value in the middle lane are less than safe headway. When the rear vehicle closes to less than a two second headway, the car-following is commonly considered to commence (Brackstone et al. 2009).

In order to classify the collected headway data, the flow scopes with the length of $100 \mathrm{pc} / \mathrm{h} / \mathrm{ln}$ were defined for each lane and the headways belonging to each 5 -minute time interval were put into the corresponding flow scope. For instance, headways belonging to the interval with flow rate of $1967 \mathrm{pc} / \mathrm{h} / \mathrm{ln}$ were put into the flow scope of 1900 to $2000 \mathrm{pc} / \mathrm{h} / \mathrm{ln}$. Five and three flow scopes were defined for the passing and middle lanes, respectively. Table 2 shows some of the characteristics of the time headways put into each flow scope.

According to the Table 2, the increase in the flow rate, resulted in a decrease in the mean and standard deviation of headways. With comparison of mean and median values for each flow scope, it is shown that the median value was less than mean value for different high levels of traffic flow. This indicates the large concentration in short headways so that $50 \%$ of the drivers choose the headway which are less than the mean of the headways.

Table 2. Characteristics of headways with separation of flow rate

\begin{tabular}{|c|c|c|c|c|c|c|c|}
\hline Position & $\begin{array}{l}\text { Flow Rate } \\
\text { Scope } \\
(\mathrm{pc} / \mathrm{h} / \mathrm{ln})\end{array}$ & $\begin{array}{l}\text { Average } \\
\text { Flow Rate } \\
(\mathrm{pc} / \mathrm{h} / \mathrm{ln})\end{array}$ & $\begin{array}{l}\text { Average } \\
\text { Speed } \\
(\mathrm{km} / \mathrm{h})\end{array}$ & $\begin{array}{l}\text { Sample } \\
\text { Size }\end{array}$ & $\begin{array}{l}\text { Mean of } \\
\text { Headways } \\
\text { (sec) }\end{array}$ & $\begin{array}{l}\text { Median of } \\
\text { Headways } \\
\quad(\mathrm{sec})\end{array}$ & $\begin{array}{c}\text { Standard } \\
\text { Deviation of } \\
\text { Headways (sec) }\end{array}$ \\
\hline \multirow{7}{*}{$\begin{array}{l}\text { Passing } \\
\text { Lane } \\
\text { (Lane 3) }\end{array}$} & $1801 \div 1900$ & 1850 & 88.36 & 267 & 2.12 & 1.50 & 1.79 \\
\hline & $1901 \div 2000$ & 1950 & 87.27 & 602 & 1.89 & 1.43 & 1.45 \\
\hline & $2001 \div 2100$ & 2050 & 88.46 & 318 & 1.79 & 1.40 & 1.34 \\
\hline & $2101 \div 2200$ & 2150 & 85.99 & 319 & 1.80 & 1.37 & 1.46 \\
\hline & $2201 \div 2300$ & 2250 & 89.75 & 542 & 1.58 & 1.23 & 1.20 \\
\hline & $2301 \div 2400$ & 2350 & 85.32 & 395 & 1.46 & 1.20 & 0.93 \\
\hline & $2401 \div 2500$ & 2450 & 87.82 & 392 & 1.47 & 1.18 & 0.98 \\
\hline \multirow{5}{*}{$\begin{array}{l}\text { Middle } \\
\text { Lane } \\
\text { (Lane 2) }\end{array}$} & $1501 \div 1600$ & 1550 & 77.51 & 478 & 2.40 & 2.11 & 1.59 \\
\hline & $1601 \div 1700$ & 1650 & 77.37 & 741 & 2.29 & 1.87 & 1.58 \\
\hline & $1701 \div 1800$ & 1750 & 81.02 & 551 & 2.03 & 1.68 & 1.28 \\
\hline & $1801 \div 1900$ & 1850 & 83.36 & 419 & 2.05 & 1.72 & 1.27 \\
\hline & $1901 \div 2000$ & 1950 & 81.53 & 155 & 1.85 & 1.56 & 1.22 \\
\hline
\end{tabular}




\section{Methodology}

In order to find an appropriate model for headway distribution, the statistical models should be used to fit the data. In this study, the shifted lognormal and the shifted gamma distributions were applied to present the headways. Lognormal is a well-known distribution model, frequently used in many studies about headways. It is also proposed to model headways under car-following situations (Greenberg 1966). The gamma distribution is another headway model widely used because of its flexibility and compatibility (Zhang et al. 2007).

The mathematical equation of the shifted lognormal distribution is:

$$
\begin{aligned}
& f(t \mid \tau, \mu, \sigma)=\frac{1}{\sigma(t-\tau) \sqrt{2 \pi}} \times \\
& \exp \left(-\frac{(\ln (t-\tau)-\mu)^{2}}{2 \sigma^{2}}\right) ; t>\tau,
\end{aligned}
$$

where: $\tau$ is the value of the shift in seconds; $\mu$ and $\sigma$ are two parameters of lognormal distribution known as location and scale parameters, respectively. They can be estimated by observed data as follows:

$$
\begin{aligned}
& \hat{\mu}=\frac{\sum_{i=1}^{n} \ln \left(t_{i}-\tau\right)}{n} ; \\
& \hat{\sigma}=\left(\frac{\sum_{i=1}^{n}\left(\ln \left(t_{i}-\tau\right)-\hat{\mu}\right)^{2}}{n-1}\right)^{\frac{1}{2}} .
\end{aligned}
$$

The mathematical equation of the shifted gamma distribution is:

$$
\begin{aligned}
& f(t \mid \tau, \alpha, \beta)=\frac{\beta^{-\alpha}(t-\tau)^{\alpha-1} e^{\left(\frac{-(t-\tau)}{\beta}\right)}}{\Gamma(\alpha)} ; t>\tau ; \\
& \Gamma(x)=\int_{0}^{\infty} y^{x-1} e^{y} d y,
\end{aligned}
$$

where: $\alpha$ and $\beta$ are two parameters of gamma distribution known as shape and scale parameters, respectively. They can be estimated by observed data as follows:

$$
\begin{aligned}
& \ln (\hat{\beta})+\psi(\hat{\alpha})=\frac{\sum_{i=1}^{n} \ln \left(t_{i}-\tau\right)}{n} ; \\
& \psi(x)=\frac{d(\ln \Gamma(x))}{d x} ; \\
& \hat{\alpha} \hat{\beta}=\frac{\sum_{i=1}^{n}\left(t_{i}-\tau\right)}{n} .
\end{aligned}
$$

To decide which of shifted distributions is the most appropriate model for headway data in each lane, the lognormal and gamma distribution models with shifts ranging from 0 to 0.75 seconds (with step of $0.015 \mathrm{sec}$ - onds) were examined. The goodness of fit of the models was checked using Chi-Square tests with 5\% level of significance. The null hypothesis for each test was as follows: 'The compatibility hypothesis of headway distribution with fitted model is rejected $(h=1)$ or not rejected $(h=0)^{\prime}$.

The process used for determining the most appropriate model for headway distribution in each lane was as follows:

Step 1: for each lane, the goodness of fit models on the distribution of total headways collected from the lane was examined.

Step 2: for each lane, the goodness of fit models on distribution of the headways occurred in each $100 \mathrm{pc} / \mathrm{h} /$ ln flow scope was examined. The flow scopes have already been presented in Table 2 .

Step 3: for each lane, the models accepted commonly in the two previous steps, were specified.

Step 4: among the models specified at the third step, the most compatible model to the data was selected as the best model for each lane. To perform that, the pvalue parameter was used. In a chi2-test with $5 \%$ level of significance, the more the $p$-value and the greater its amount than 0.05 , the more compatible the model is.

Step 5: using the selected model for each lane, the headway distribution diagrams were obtained for different levels of traffic flow. This allowed a direct conversion from traffic flow rates to corresponding headway distributions for each lane.

\section{Results and Discussion}

The results of modeling time headway distributions are presented as follow:

Step 1: for each lane, the goodness of fit models on the distribution of total headways collected from the lane was examined. In this step, $204 \mathrm{Chi}$-Square tests were done for models with different shifts using MATLAB software (http://www.mathworks.se). For each test, the parameters of the model were estimated from the headway data. The results of each step are presented in Table 3. It shows values of ' $h$ ' for Chi-Square tests on all headways collected from each one of two lanes. The equation of ' $h$ ' with 1 , represents rejection of test and its equation with 0 , represents approval of the test.

As it is shown in Table 3, the lognormal distribution models with shifts ranging from 0.135 to $0.27 \mathrm{sec}-$ onds were well-fitted to headways in the passing lane. Nevertheless, none of the shifted lognormal models were fitted appropriately to headways in the middle lane. Thus, it can be claimed that lognormal model is not proper for headway distribution in the middle lane. Meanwhile, the results of fitting the gamma distribution models with different shifts on headways in the passing lane shows that the gamma model is not proper for modeling headways in it. However, gamma models with shifts ranging from 0.495 to 0.75 seconds were wellfitted to headways in lane 2. Then, the selected models for passing and middle lanes are shifted lognormal and shifted gamma, respectively. 
Table 3. Results of chi2- tests for distribution of totalheadways in each lane

\begin{tabular}{|c|c|c|c|c|}
\hline \multirow{2}{*}{$\begin{array}{c}h^{\star} \\
\text { Shift } \\
(\mathrm{Sec})\end{array}$} & \multicolumn{2}{|c|}{ Lane 3} & \multicolumn{2}{|c|}{ Lane 2} \\
\hline & $\begin{array}{c}\text { Lognor- } \\
\text { mal }\end{array}$ & Gamma & $\begin{array}{c}\text { Lognor- } \\
\text { mal }\end{array}$ & Gamma \\
\hline 0.000 & 1 & 1 & 1 & 1 \\
\hline 0.015 & 1 & 1 & 1 & 1 \\
\hline 0.030 & 1 & 1 & 1 & 1 \\
\hline 0.045 & 1 & 1 & 1 & 1 \\
\hline 0.060 & 1 & 1 & 1 & 1 \\
\hline 0.075 & 1 & 1 & 1 & 1 \\
\hline 0.090 & 1 & 1 & 1 & 1 \\
\hline 0.105 & 1 & 1 & 1 & 1 \\
\hline 0.120 & 1 & 1 & 1 & 1 \\
\hline 0.135 & 0 & 1 & 1 & 1 \\
\hline 0.150 & 0 & 1 & 1 & 1 \\
\hline 0.165 & 0 & 1 & 1 & 1 \\
\hline 0.180 & 0 & 1 & 1 & 1 \\
\hline 0.195 & 0 & 1 & 1 & 1 \\
\hline 0.210 & 0 & 1 & 1 & 1 \\
\hline 0.225 & 0 & 1 & 1 & 1 \\
\hline 0.240 & 0 & 1 & 1 & 1 \\
\hline 0.255 & 0 & 1 & 1 & 1 \\
\hline 0.270 & 0 & 1 & 1 & 1 \\
\hline 0.285 & 1 & 1 & 1 & 1 \\
\hline 0.30 & 1 & 1 & 1 & 1 \\
\hline 0.315 & 1 & 1 & 1 & 1 \\
\hline 0.330 & 1 & 1 & 1 & 1 \\
\hline 0.345 & 1 & 1 & 1 & 1 \\
\hline 0.360 & 1 & 1 & 1 & 1 \\
\hline 0.375 & 1 & 1 & 1 & 1 \\
\hline 0.390 & 1 & 1 & 1 & 1 \\
\hline 0.405 & 1 & 1 & 1 & 1 \\
\hline 0.420 & 1 & 1 & 1 & 1 \\
\hline 0.435 & 1 & 1 & 1 & 1 \\
\hline 0.450 & 1 & 1 & 1 & 1 \\
\hline 0.465 & 1 & 1 & 1 & 1 \\
\hline 0.480 & 1 & 1 & 1 & 1 \\
\hline 0.495 & 1 & 1 & 1 & 0 \\
\hline 0.510 & 1 & 1 & 1 & 0 \\
\hline 0.525 & 1 & 1 & 1 & 0 \\
\hline 0.540 & 1 & 1 & 1 & 0 \\
\hline 0.555 & 1 & 1 & 1 & 0 \\
\hline 0.570 & 1 & 1 & 1 & 0 \\
\hline 0.585 & 1 & 1 & 1 & 0 \\
\hline 0.600 & 1 & 1 & 1 & 0 \\
\hline 0.615 & 1 & 1 & 1 & 0 \\
\hline 0.630 & 1 & 1 & 1 & 0 \\
\hline 0.645 & 1 & 1 & 1 & 0 \\
\hline 0.660 & 1 & 1 & 1 & 0 \\
\hline 0.675 & 1 & 1 & 1 & 0 \\
\hline 0.690 & 1 & 1 & 1 & 0 \\
\hline 0.705 & 1 & 1 & 1 & 0 \\
\hline 0.720 & 1 & 1 & 1 & 0 \\
\hline 0.735 & 1 & 1 & 1 & 0 \\
\hline 0.750 & 1 & 1 & 1 & 0 \\
\hline
\end{tabular}

Step 2: for each lane, the goodness of fit of models on distribution of the headways occurred in each $100 \mathrm{pc} / \mathrm{h} / \mathrm{ln}$ flow scope was examined. In this step, 561 Chi-Square tests were done by MATLAB software. The lognormal models with different shifts were fitted on headway data from each flow scope of the passing lane (lane 3). For the middle lane (lane 2), the same procedure was done using shifted gamma models. Table 4 shows the ranges of the accepted models for headway distributions.

Step 3: for each lane, the models accepted and approved commonly in the two previous steps, were specified. For each lane, the common range of the accepted models was considered.

Table 4. Ranges of accepted models for headway distributions

\begin{tabular}{|c|c|c|c|}
\hline Position & $\begin{array}{c}\text { Appropriate } \\
\text { Model }\end{array}$ & $\begin{array}{l}\text { Flow Rate } \\
(\mathrm{pc} / \mathrm{h} / \mathrm{ln})\end{array}$ & $\begin{array}{c}\text { Range of } \\
\text { Not Rejected } \\
\text { Shifts (sec) }\end{array}$ \\
\hline \multirow{8}{*}{$\begin{array}{l}\text { Passing lane } \\
\text { (lane 3) }\end{array}$} & \multirow{8}{*}{$\begin{array}{c}\text { Shifted } \\
\text { Lognormal }\end{array}$} & Total data & $0.135 \div 0.270$ \\
\hline & & $1801 \div 1900$ & $0.000 \div 0.435$ \\
\hline & & $1901 \div 2000$ & $0.090 \div 0.315$ \\
\hline & & $2001 \div 2100$ & $0.000 \div 0.285$ \\
\hline & & $2101 \div 2200$ & $0.000 \div 0.435$ \\
\hline & & $2201 \div 2300$ & $0.000 \div 0.435$ \\
\hline & & $2301 \div 2400$ & $0.000 \div 0.285$ \\
\hline & & $2401 \div 2500$ & $0.000 \div 0.285$ \\
\hline \multirow{5}{*}{$\begin{array}{l}\text { Middle lane } \\
\text { (lane 2) }\end{array}$} & \multirow{5}{*}{$\begin{array}{l}\text { Shifted } \\
\text { Gamma }\end{array}$} & Total data & $0.495 \div 0.750$ \\
\hline & & $1501 \div 1600$ & $0.570 \div 0.750$ \\
\hline & & $1601 \div 1700$ & $0.210 \div 0.750$ \\
\hline & & $1701 \div 1800$ & $0.645 \div 0.750$ \\
\hline & & $1801 \div 1900$ & $0.465 \div 0.750$ \\
\hline
\end{tabular}

On the basis of that, the lognormal distributions with shifts ranging from 0.135 to 0.27 were the proper models for lane 3. For lane 2, the gamma distributions with shifts ranging from 0.645 to 0.75 seconds were identified as the proper models.

Step 4: among the models specified at the previous step, the model with the highest $p$-value was selected as the best one. Table 5 shows the $p$-value results of $\mathrm{Chi}$ Square tests for all headways. It is shown that for the passing lane, the lognormal model with shift of $0.24 \mathrm{sec}-$ onds got the higher $p$-value. So, it is the best model for passing lane. Similarly, the gamma model with shift of 0.69 seconds is the most appropriate model for the middle lane. Fig. 2 exhibits the probability density functions for observed data and the selected model in each lane.

Step 5: In step 2, the lognormal distribution model with 0.24 seconds shift was fitted on headways occurred in each $100 \mathrm{pc} / \mathrm{h} / \mathrm{ln}$ flow scope. For each fitting process, two parameters of the model (location and scale parameters) were estimated from the headway data. Also, for each flow scope, the average of starting and ending flow rate was determined as the mean flow rate of the scope. 
a)

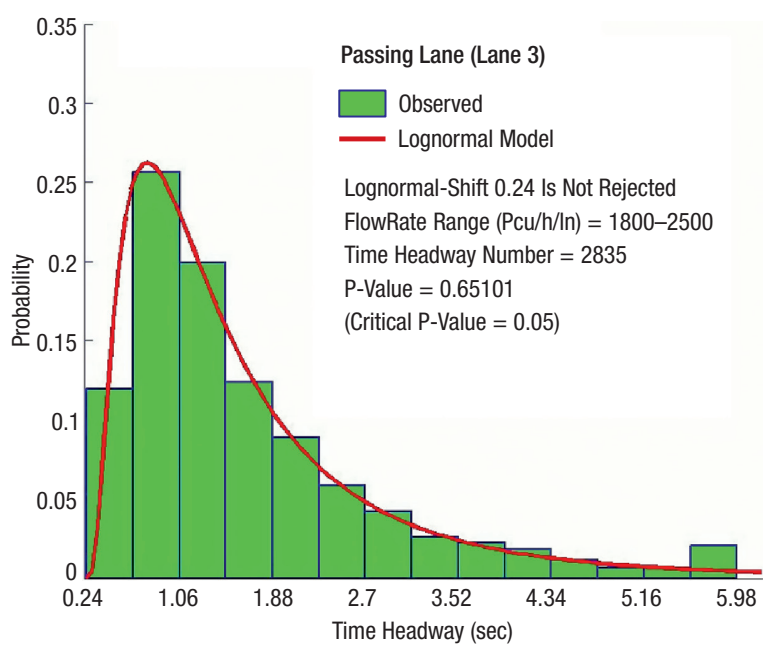

b)

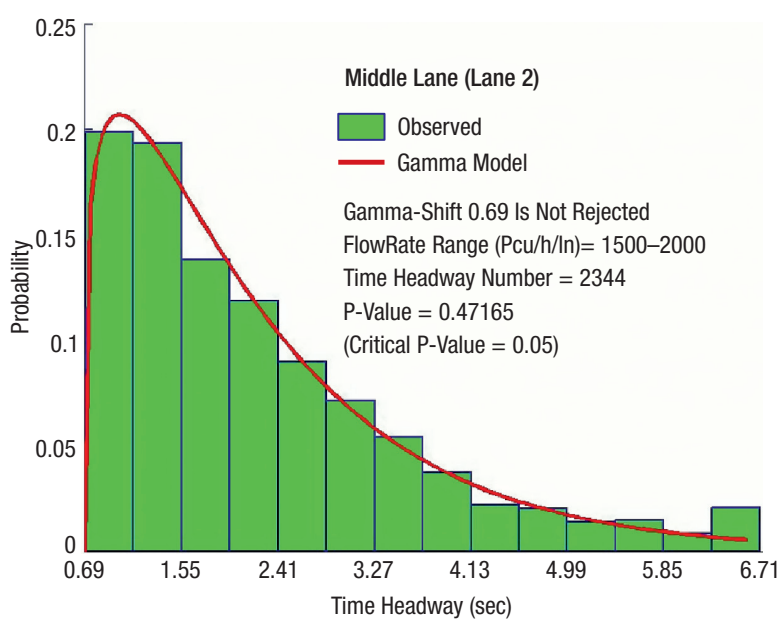

Fig. 2. Selected models fitted on the distribution of total observed headways of lanes: a - passing lane (lane 3); $\mathrm{b}$ - middle lane (lane 2)

Then, each estimated parameter was corresponded to a mean flow rate. Then, the parameters could be calculated as a function of mean flow rate in the passing lane:

$$
\begin{aligned}
& \text { for location parameter: } \\
& \mu=1.323567-0.0005796 \cdot F \quad\left(R^{2}=0.95\right) ; \\
& \text { for scale parameter: } \\
& \sigma=1.181167-0.0001686 \cdot F \quad\left(R^{2}=0.65\right),
\end{aligned}
$$

where: $F$ is the mean flow rate in $\mathrm{pc} / \mathrm{h} / \mathrm{ln}$. Similarly for the middle lane, the parameters of the gamma distribution model with 0.69 seconds shift could be calculated:

$$
\begin{aligned}
& \text { for shape parameter: } \\
& \alpha=-0.32629+0.0009118 \cdot F \quad\left(R^{2}=0.95\right) \text {; } \\
& \text { for scale parameter: } \\
& \beta=4.742495-0.002010 \cdot F \quad\left(R^{2}=0.92\right) .
\end{aligned}
$$

By having the parameters of each model, the headway distributions can be obtained for different flow rates in each lane. Fig. 3 shows the results.
At the peak hours of traffic flow, the maximum observed flow rate at which vehicles can reasonably pass is $2450 \mathrm{pc} / \mathrm{h} / \mathrm{ln}$ in the passing lane. This shows that the real capacity of the lane is something about this amount. While, for the middle lane, the corresponding value is about $1950 \mathrm{pc} / \mathrm{h} / \mathrm{ln}$. The specific behavioral pattern of drivers in the passing lane and their propensity to tailgate with high speeds, caused difference of capacity and safety in the lanes. Based on the results of model shown in Fig. 3b for the passing lane, at the flow rates near the capacity $(2450 \mathrm{pc} / \mathrm{h} / \mathrm{ln}), 50 \%$ of drivers choose headway less than 1.15 seconds (the corresponding value for observed data is 1.18). While the median of headways near the middle lane capacity $(1950 \mathrm{pc} / \mathrm{h} / \mathrm{ln})$ is 1.63 seconds as shown in Fig. 3d (the corresponding value for observed data is 1.56).

Different behavioral variables such as unexpected braking of vehicles and lane changing lead to time headway reduction (Kerner 2009).

To evaluate the reason of different selected models for the lanes and its relation with the car-following behavior more precisely, we can remove the effect of flow rate. Thus, for the same flow scopes, the statistical criteria such as mean, median and standard deviation values were calculated based on the selected models and were compared with observed data. The results are presented in Table 5. According to the Table 5, at the same flow scopes, the mean value of headways in the passing lane is a little higher than the one in the middle lane. While, the median value of headways in the passing lane is less than one in the middle lane. This issue is satisfied for both the model and the observed data and is the reason for the different obtained distributions in the lanes. This shows that the car-following behaviors are different, even at the same flows in different lanes.

Also, at the same flows, the speed of vehicles in the

\begin{tabular}{|c|c|c|c|c|c|c|c|}
\hline \multirow{2}{*}{$\begin{array}{l}\text { Flow Rate } \\
\text { Scope } \\
(\mathrm{pc} / \mathrm{h} / \mathrm{ln})\end{array}$} & \multirow{2}{*}{ Lane } & \multicolumn{2}{|c|}{ Mean $(\mathrm{sec})$} & \multicolumn{2}{|c|}{ Median (sec) } & \multicolumn{2}{|c|}{ Std. (sec) } \\
\hline & & $\mathrm{M}^{*}$ & O. & M. & O. & M. & O. \\
\hline \multirow{2}{*}{$1800 \div 1900$} & 3 & 2.12 & 2.12 & 1.53 & 1.50 & 1.99 & 1.79 \\
\hline & 2 & 2.08 & 2.05 & 1.76 & 1.72 & 1.2 & 1.27 \\
\hline \multirow{2}{*}{$1900 \div 2000$} & 3 & 1.98 & 1.89 & 1.45 & 1.43 & 1.8 & 1.45 \\
\hline & 2 & 1.89 & 1.85 & 1.63 & 1.56 & 0.99 & 1.22 \\
\hline \multicolumn{8}{|c|}{$\begin{array}{l}\text { M.*: Model; } \\
\text { O.*: Observed }\end{array}$} \\
\hline
\end{tabular}
passing lane and dispersal of headways are more and this is because at the same flow conditions, the drivers in the middle lane move closer to the lane capacity level compared to drivers in passing lane. Therefore, their headways are close to each other.

Table 5. Comparison of characteristics of headways for lanes at the same flow 
a)

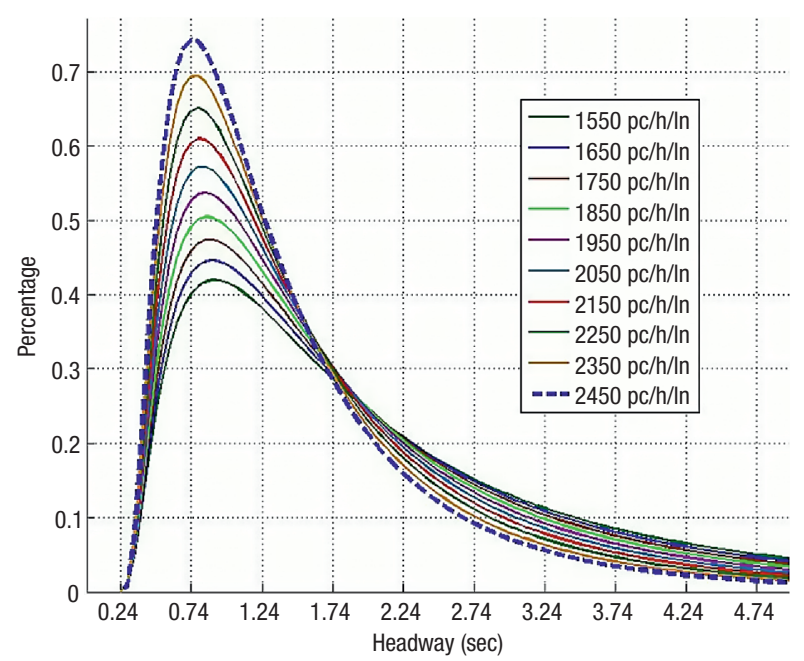

c)

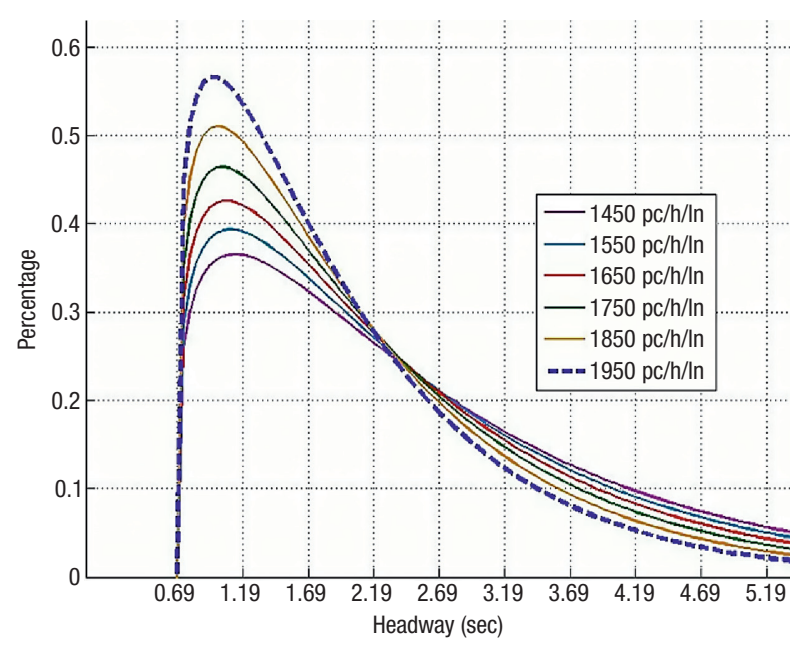

b)

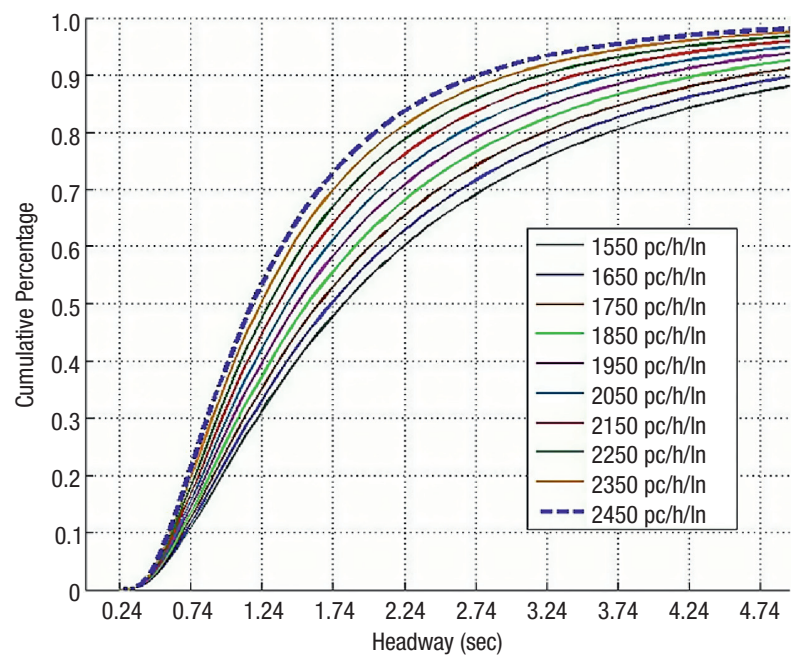

d)

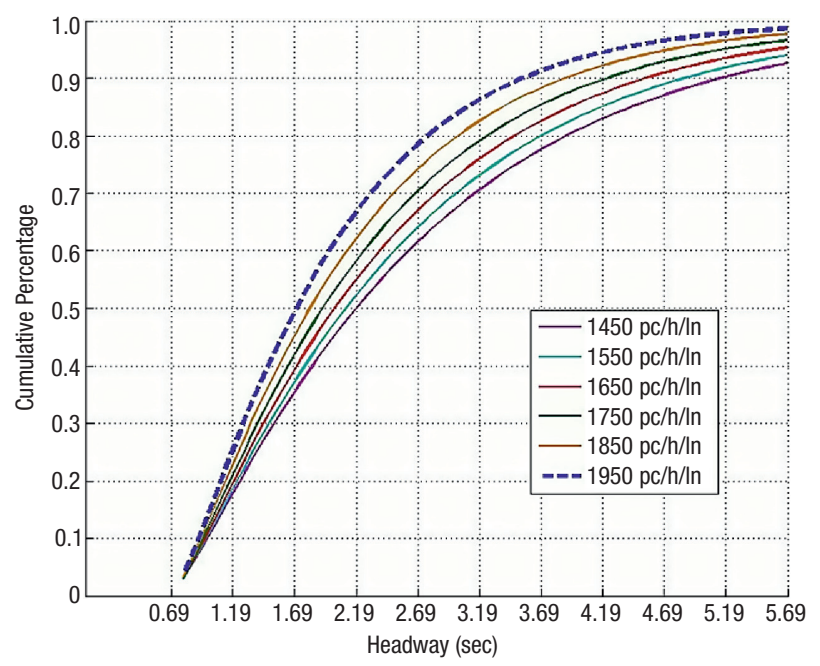

Fig. 3. Predicted headway distributions: a - probable density function of headways in lane 3; b - cumulative density function of headways in lane 3; c - probable density function of headways in lane 2; $\mathrm{d}$ - cumulative density function of headways in lane 2

\section{Conclusions}

The present study was performed to investigate the time headway distributions at urban multi-lane highways. The Iranian drivers' behaviors in choosing the headway were analyzed within high levels of traffic flow. Some of the results are listed below:

1. In the car-following conditions, a large number of drivers adopt headways which are less than safe headway. A comparison of mean and median values indicates that at all flow scopes, the median is less than mean. It reveals the concentration of short headways; in a way that $50 \%$ of drivers choose headways less than mean. This is because of a high risk-ability of driver population which results in safety reduction.

2. The results of modeling shows that the appropriate models for headway distribution are different in the passing and middle lanes under heavy traffic conditions. The lognormal model with 0.24 seconds shift was selected as the appropriate model for headway distribution of the passing lane. For the middle lane, the gamma model with 0.69 seconds shift was selected as the most appropriate model. This is because of different behavioral operation of drivers which is affected by specific conditions of each lane.

3. Because of the specific pattern of drivers for car-following in the passing lane and their propensity to tailgate with high speed at peak hours of traffic flow, the capacity of the passing lane is higher than one for the middle lane and thus, the distributions and statistical criteria are considerably different for the lanes.

4. The car-following behaviors are different, even at the same flows in different lanes.

\section{Acknowledgement}

The authors would like to express their sincere thanks and appreciations to Isfahan Municipality for their praiseworthy cooperation with us in implementing this research. 


\section{References}

Al-Ghamdi, A. S. 2001. Analysis of time headways on urban roads: case study from Riyadh, Journal of Transportation Engineering 127(4): 289-294. doi:10.1061/(ASCE)0733-947X(2001)127:4(289)

Bham, G. H.; Ancha, S. R. P. 2006. Statistical models for preferred time headway and time headway of drivers in steady state car-following, in Applications of Advanced Technology in Transportation: Proceedings of the Ninth International Conference. 13-16 August 2006, Chicago, Illinois, USA, 344-349. doi:10.1061/40799(213)54

Brackstone, M.; Waterson, B.; McDonald, M. 2009. Determinants of following headway in congested traffic, Transportation Research Part F: Traffic Psychology and Behaviour 12(2): 131-142. doi:10.1016/j.trf.2008.09.003

Daisuke, S.; Izumi, O.; Fumihiko, N. 1999. On estimation of vehicular time headway distribution parameters, Traffic Engineering 34(6): 18-27.

Greenberg, I. 1966. The log-normal distribution of headways, Australian Road Research 2(7): 14-18.

Highway Capacity Manual. 2000. Transportation Research Board, National Research Council. Washington, U.S.A. $1134 \mathrm{p}$.

Jakimavicius, M.; Burinskiene, M. 2009. A GIS and multi-criteria-based analysis and ranking of transportation zones of Vilnius city, Technological and Economic Development of Economy 15(1): 39-48. doi:10.3846/1392-8619.2009.15.39-48

Kerner, B. S. 2009. Introduction to Modern Traffic Flow Theory and Control: the Long Road to Three-Phase Traffic Theory. 1st edition. Springer. 278 p.

Luttinen, R. T. 1994. Identification and estimation of headway distributions, in Procedings of the 2nd International Symposium on Highway Capacity. Sydney, Australia, 427-446.

Luttinen, R. T. 1996. Statistical Analysis of Vehicle Time Headways: Doctoral Dissertation. Helsinki University of Technology, Finland. 193 p. Available from Internet: <http://lib. tkk.fi/Diss/199X/isbn951228474X/isbn951228474X.pdf>.

Mei, M.; Bullen, A. G. R. 1993. Lognormal distribution for high traffic flows, Transportation Research Record 1398: $125-128$

Mesarec, B.; Lep, M. 2009. Combining the grid-based spatial planning and network-based transport planning, Technological and Economic Development of Economy 15(1): 6077. doi:10.3846/1392-8619.2009.15.60-77

Michael, P. G.; Leeming, F. C.; Dwyer, W. O. 2000. Headway on urban streets: observational data and an intervention to decrease tailgating, Transportation Research Part F: Traffic Psychology and Behaviour 3(2): 55-64. doi:10.1016/S1369-8478(00)00015-2

Sadeghhosseini, S. 2002. Time Headway And Platooning Characteristics of Vehicles on Interstate Highways: $\mathrm{PhD}$. Dissertation. University of Illinois, USA. 360 p.

Thamizh Arasan, V.; Koshy, R. Z. 2003. Headway distribution of heterogeneous traffic on urban arterials, Journal of the Institution of Engineers 84: 210-215.

Yi, P.; Zhang, Y.; Lu, J.; Lu, H. 2004. Safety-based capacity analysis for Chinese highways - a preliminary study, IATSS Research 28(1): 47-55.
Zhang, G.; Wang, Y.; Wei, H.; Chen, Y. 2007. Examining headway distribution models with urban freeway loop event data, Transportation Research Record 1999: 141-149. doi:10.3141/1999-15

Zwahlen, H. T.; Oner, E.; Suravaram, K. 2007. Approximated headway distributions of free-flowing traffic on Ohio freeways for work zone traffic simulations, Transportation Research Record 1999: 131-140. doi:10.3141/1999-14 